\title{
Diffuse lung disease caused by cotton dust exposure
}

\begin{abstract}
Byssinosis is an occupational lung disease caused by the inhalation of cotton, flax and hemp fibers. Workers from all levels of cotton processing carding, blowing, spinning and weaving- are exposed to cotton dust. We present a case of Byssinosis in a 28year-old man working at a cotton factory for 6years. He presented to the emergency department with cough, breathlessness and fever.
\end{abstract}

Keywords: inhalation of cotton, byssinosis, pulmonary fibrosis, pneumoconiosis,

clinical examination
Volume 5 Issue 6 - 2018

\author{
Balakrishnan Menon,' Parul Mrigpuri, ${ }^{2}$ Mani \\ Tiwari, ${ }^{3}$ Praveen Raj ${ }^{4}$ \\ Department of Pulmonary Medicine, University of Delhi, India
}

Correspondence: Balakrishnan Menon, Department of Pulmonary Medicine, Vallabhbhai Patel Chest Institute, University of Delhi, India, Email balakrishnan.menon@rediffmail.com

Received: June 14,2018 | Published: November 19, 2018

\section{Background}

In India, 20million workers are involved in the manufacturing of textiles. ${ }^{1}$ Byssinosis is caused by the inhalation of cotton, jute, flax and hemp fibers. It is a type of hypersensitivity pneumonitis. Byssinosis is characterized by acute breathlessness, cough, and wheeze, typically on Monday mornings following a weekend away from the workplace; symptoms decrease during the work week despite continued exposure. The prevalence and severity of symptoms and functional impairment are proportional to the duration and intensity of exposure. ${ }^{2}$ Although the pathogenesis of Byssinosis is unclear, the disorder shares some features with hypersensitivity pneumonitis: Both frequently occur after exposure to dust, and affected patients improve rapidly without therapy. ${ }^{2,3}$ There have been only a few reports of pulmonary fibrosis and pneumoconiosis due to cotton dust. ${ }^{4}$

\section{Case report}

A 36year-old male with history of smoking and a pack year of 10 , presented with symptoms of persistent dry irritating cough with gradually increasing intensity for the past 18 months becoming spasmodic, with production of small quantities of sticky, tenacious sputum. He also had progressive breathlessness for 18 months and has history of repeated episodes of fever. These symptoms are aggravated when he returned to work after weekends and vacations. There was no history of haemoptysis, joint pain or skin rashes. He was working in Cotton factory 8-10hours/day for past 6years, and was involved in the making of cotton mattress and blankets. Although cotton fibers were often floating in the atmosphere of the workroom, no respiratory protection for the dust was provided. On clinical examination, the patient had Modified Medical Research Council (MMRC) dyspnoea scale of 2 and hypoxemia with a saturation of $81 \%$ at room air. On examination of the chest, there was vesicular breath sounds in both lung fields with scattered fine crackles. Chest radiograph shows diffuse, ill-defined haziness, predominantly in the lower lung zones (Figure 1).

Serological tests showed no evidence of collagen disease. Arterial blood gas analysis revealed a $\mathrm{pH}$ of $7.474, \mathrm{PaCO} 2$ of $36.2 \mathrm{~mm} \mathrm{Hg}$, and $\mathrm{PaO} 2$ of $56.2 \mathrm{~mm} \mathrm{Hg}$. Lung function tests gave the following results: vital capacity 1.261 (38\% of predicted), forced expiratory volume in 1 second/forced vital capacity (FEV1/FVC) 94\%, peak expiratory flow $4.741 / \mathrm{min}$ (58\% of predicted), and carbon monoxide transfer factor (TLCO) $5.53 \mathrm{ml} / \mathrm{min} / \mathrm{mm} \mathrm{Hg}$ (19\% of predicted) suggesting severe restriction. Maximal mid expiratory flow was $2.761 / \mathrm{s}(76 \%$ of predicted) and $25 \%$ forced expiratory flow was $4.611 / \mathrm{s}(61 \%$ of predicted). Patient underwent Bronchoscopy and transbronchial lung biopsy. Analysis of bronchoalveolar lavage fluid revealed a cell count of $2.2610^{5} / \mathrm{ml}$ with $15 \%$ lymphocytes and $85 \%$ macrophages. No histopathological features ${ }^{5}$ characteristic of Byssinosis such as mucus gland hyperplasia and infiltration of neutrophils into the bronchi were seen. ${ }^{6,7}$ There was also no eosinophilic infiltration (reflecting allergy) in the biopsy specimens. High-resolution CT scan (mediastinal window) shows diffuse mild pleural thickening on both sides (Figure 2A) (Figure 2B). High-resolution CT scan (lung window) shows thickened intralobular and interlobular lines, hazy patches of increased attenuation, bilateral small cysts predominantly in peripheral and subpleural distribution with associated traction bronchiectasis, and areas of ground-glass attenuation (Figures 3A-3E). A diagnosis of cotton dust pneumoconiosis was suggested by occupational exposure and a bronchiolocentric distribution of lung changes on the HRCT scan.

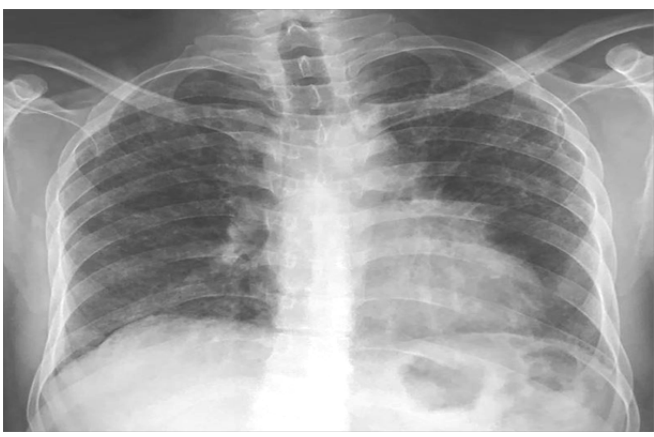

Figure I Chest radiograph shows diffuse, ill-defined haziness, predominantly in the lower lung zones.
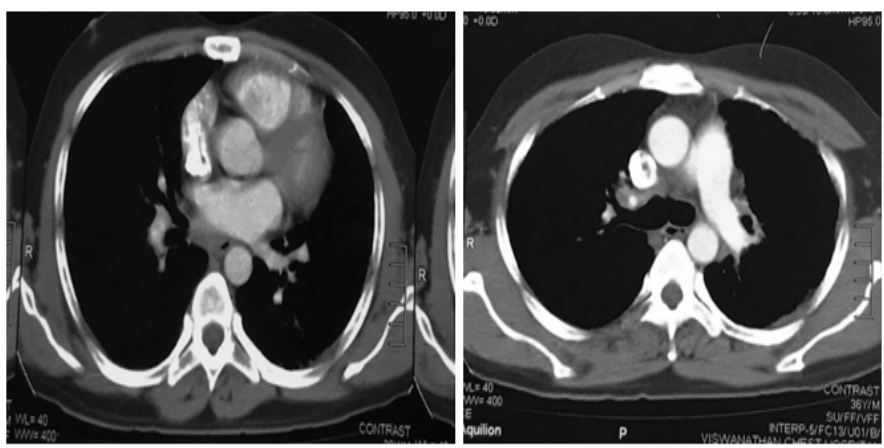

Figure 2(A\&B) High-resolution CT scan (mediastinal window) shows diffuse mild pleural thickening on both sides. 

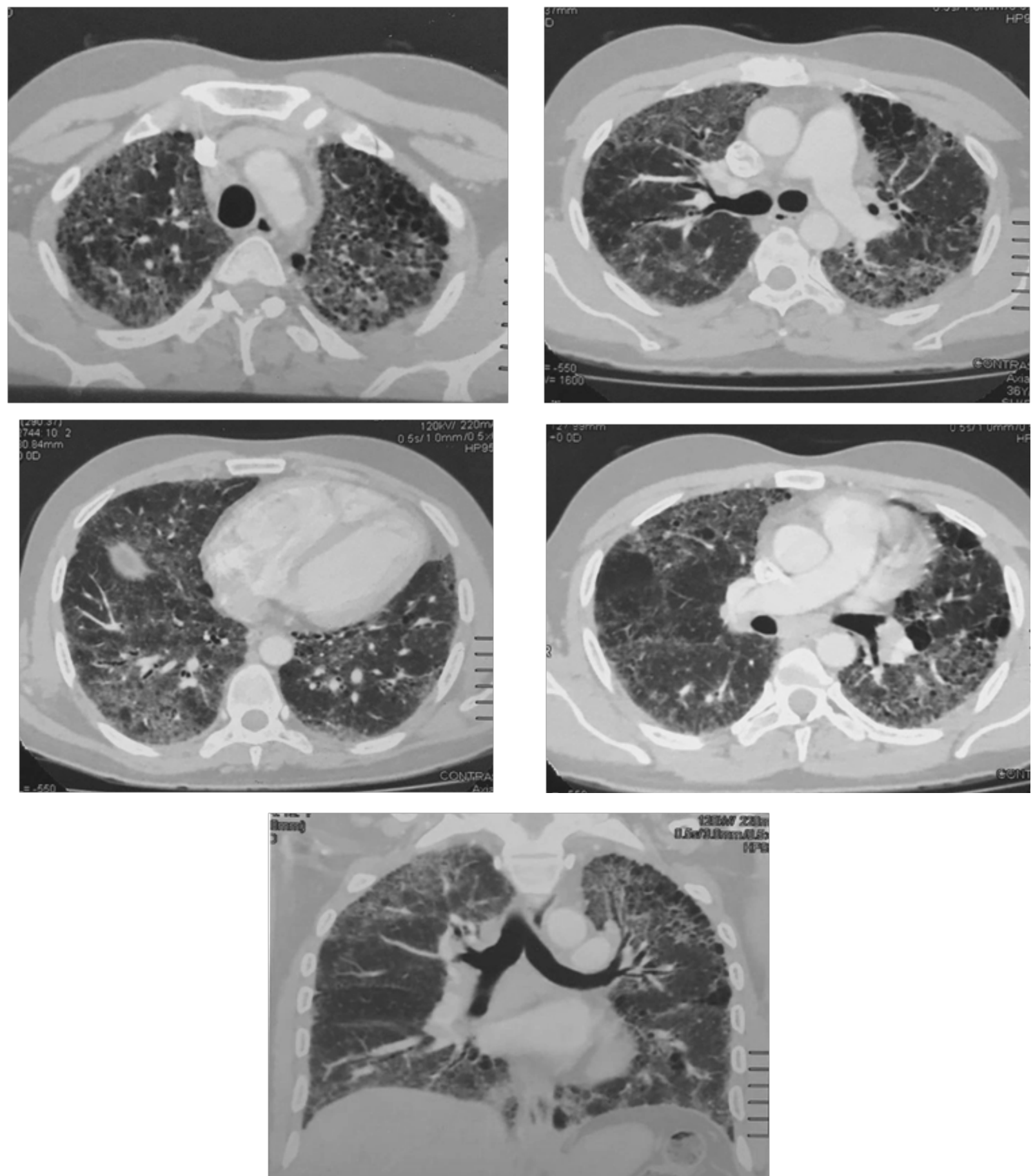

Figure 3(A-E) High-resolution CT scan (lung window) shows thickened intralobular and interlobular lines, hazy patches of increased attenuation, bilateral small cysts predominantly in peripheral and sub-pleural distribution with associated traction bronchiectasis, and areas of ground-glass attenuation.

\section{Discussion}

Some occupational lung diseases have characteristic radiologic features suggesting the diagnosis while others do not. In such diseases, definite diagnosis cannot be made on the basis of imaging features alone, but a combination of clinical features with related occupational history and radiologic findings can significantly improve diagnostic accuracy. The patient described here had symptoms of Byssinosis (cough, breathlessness and Monday morning fever). The lung function tests also showed the severe restriction. X-ray and HRCT showed features consistent with Byssinosis.

\section{Acknowledgements}

None.

\section{Conflict of interest}

Author declares that there is no conflict of interest. 


\section{References}

1. Awdesh Mishra. Byssinosis among male textile workers in Pondicherry: A case-control study. The National medical journal of India. 2003;16(2):70-73.

2. Fraser RS, Muller NL, Colman N, et al. Diagnosis of diseases of the chest. 4th ed. Philadelphia: Saunders; 1999

3. McL Niven R, Pickering CA. Byssinosis: a review. Thorax. 1996;51(6):632-637.
4. Abe A, Ishikawa T. Studies on pneumoconiosis caused by organic dusts (Japanese). J Sci Labour. 1967;43:19-41.

5. Edwards C, McCartney J, Rooke G, et al. The pathology of the lung in byssinotics. Thorax. 1975;30(6):612-623.

6. Sano T. Pathology and pathogenesis of organic dust pneumoconiosis. $J$ Sci Labour. 1967;43:3-18.

7. Rooke GB. The pathology of Byssinosis. International conference on Byssinosis. Chest. 1981;79(Suppl):S67-S71. 